\title{
Prevalence of Syndromic Intellectual Disability among Children of Age 2-5 Years in Different Hospitals of Lahore, Punjab
}

\author{
Shagufta Naz*, Eesha Sajjad, Sumaima Kokab, Saima Sharif
}

1. Department of Zoology, Lahore College for Women University, Jail Road Lahore, Pakistan.

* Corresponding Author's Email: shagufta6@gmail.com

ABSTRACT: A retrospective analytical study was performed from September 2019 to March 2020 on Intellectual disability patients by visiting different hospitals of Lahore, Punjab. The aim of this research was to determine the prevalence of different factors associated with syndromic intellectual disability in the Punjab population. Intellectual Disability (ID) is caused by the environmental influence, genetic disorder, perinatal infection, neonatal infection or postnatal infection. It was diagnosed by the test of Intellectual functioning. In this study 50 patients were identified among which 33 were males and 17 were females. The basic cause of ID in Pakistan was recorded as cousin marriages. Other factors like malnutrition, microcephaly, complicated delivery, brain infections were the major causes of ID. To avoid severe or profound ID early diagnosis, clinical evaluation, genetic counseling, and proper treatment was necessary. A proper guidance must require for the parents to admit their ID children in respective special school. The primary goal of this research was to provide information to individuals and groups who were recognized to be at risk for ID, as well as their family members and to those who deal with them.

Keywords: Prevalence, syndromic, Intellectual Disability, Punjab

\section{INTRODUCTION}

\section{Intellectual disability (ID), also}

known as general learning disability (GLD) and mental retardation (MR) is a condition marked by considerable limits in both intellectual functioning and adaptive behavior, which includes everyday social and practical abilities (Maulik et al., 2013). A person with an Intellectual Disability is limited in two ways. Intellectual functioning, often known as IQ, is the ability of a person to learn, reason, make decisions, and solve issues. The condition affects children under the age of 18 and is linked to a 
variety of biological, environmental and societal factors (Guralnick, 2005; Brereton et al., 2006; Schalock et al., 2007).

An IQ exam is used to determine ones IQ (intelligence quotient). The average IQ score is 100 , with the majority of persons scoring in the 85-115 range. If a person's IQ is between 70 and 75 , he or she is called intellectual. A professional will observe the child's skills and compare them to those of the other children of the same age to determine the child's adaptive behaviors. The child's ability to feed and dress himself, as well as his or her ability to speak with and understand people, and how the child interacts with family, friends and other children of same age are all things that can be seen (Daily et al., 2000).

Environmental and/or genetic factors can induce ID. However, in up to $60 \%$ of cases, no clear cause may be found (Rauch et al., 2006). ID can be caused by teratogens, viruses, or radiation in the environment, as well as severe head trauma or injury resulting in a lack of oxygen to the brain. While these factors may explain certain occurrences of NSID, genetic aetiology must also be considered. Genetic causes of ID are estimated to be present in $25-50 \%$ of instances, albeit this figure rises in proportion to the severity of the condition (McLaren and Bryson, 1987; Rauch et al., 2012). In ID, a wide spectrum of chromosomal abnormalities has been observed, with many different types of aberrations being found (Ropers, 2006;
Rauch et al., 2006). Malnutrition is a prevalent cause of lowered intelligence in areas of the world where there is famine, such as Ethiopia and countries where agriculture production and distribution are disrupted by long periods of warfare (Wines, 2006).

Pakistan has one of the world's highest rates of reported childhood intellectual disability (ID). In low-income countries, the prevalence of intellectual disability is two to eight times higher than in industrialized countries (Durkin et al., 2002). With a population of 160 million people, 45 percent of whom are under the age of 18, Pakistan has higher than predicted rates of intellectual disability. Our data imply that detecting ID takes a long time, particularly in rural areas, where more than $70 \%$ of Pakistan's population lives. There is a need to develop community-level interventions that are practicable, cost-effective, and can be integrated into current healthcare systems (Durkin et al., 1998).

However, there are gaps and very scarce data is reported with reference to ID in Pakistan. T is known that interviews with parents, observation of the kid, and testing of IQ and adaptive behaviors all play a role in the diagnosis of intellectual disability. If a child's IQ and adaptive behaviors are both below average, he or she is deemed intellectually handicapped. The child is not regarded cognitively impaired if only one or the other is present. A team of professionals will assess the child's specific strengths and weaknesses after an intellectual disability 
diagnosis has been made. This study aimed to figure out how much and what type of aid the child will require at home, in school, and in the community so a detailed survey was conducted to obtained the information regarding ID.

\section{MATERIAL AND METHODS}

Patients affected with Intellectual disability were searched by visiting different hospitals of Lahore, Punjab. Hospital records of the ID patients were assessed. The staff of these hospitals and institutes was very supportive and accommodating and assisted in providing all the data with complete information about the patients of the ID. The institutes also organized the parents meet up with us so that we can get the complete information about their children. The duration of study is from September 2019 to March 2020. The research study involved 50 subjects. Study participants provided with a protocol approved by respective Hospital's management or Institute's management. Complete examination was performed and participants were classified with ID if they showed any relevant symptom.

Case files of patients with Intellectual disability were assessed. The variables analyzed were age, gender, residence, IQ level, family, genetic disorder, environment influence, perinatal infection, Neonatal infection, Postnatal brain infection, Postnatal Head injury, Physical disorder associated with ID, Signs of Disabilities with ID, Mental Stress, Birth trauma, and Single gene disorder.
Questionnaires were filled by the parents to diagnose the condition of child. If any one question showed possible disability, a kid was regarded to have screened positive for any handicap. The questionnaire was translated into Urdu and given to a parent or guardian during a personal interview. Patients of Intellectual disability were identified by doctors in the hospitals, special institute and people from different areas of Punjab. The data has been collected of children of the different ages living in different areas of Punjab, an area introverted by millions of people. This was achieved by haphazardly selecting a number of patients to study them. A group of local psychologists and physicians conducted clinical assessments on the children. The physician's diagnosis of ID was based on the child's developmental history as well as a structured observation of the child's language, follow-through, motor abilities, and conduct. Psychologists classified the severity of ID based on the intelligence quotient: 50-70 for mild, 35-49 for moderate, and $<35$ for severe. All survey, screening, and psychological and medical evaluation data was captured on preprinted forms, then entered into a computerized database and connected by identifying numbers. Before and after the data was input into the database, accuracy checks and necessary corrections were performed. The percentage of children obtained with negative screening results was evaluated; the data for these children were weighted in the analysis. Chi square test was also performed. 
RESULTS AND DISCUSSION

Patients affected with Intellectual disability were searched by visiting Service hospital, Children hospital, Society institute for special children and government institute for special children. All the cases were registered, and the registry provides a rare opportunity for studying childhood disability at the national level. Among approximately 500 patient's studies 50 cases of Intellectual disability were identified which include $66 \%(\mathrm{~N}=33)$ males and $34 \%(\mathrm{~N}=17)$ females. Prevalence of gender, age and residence related to ID were recorded that was high in males, kids and urban respectively and shown in table 1,2 , and 3.

Table 1: Gender distribution of patients with Intellectual Disability (ID)

\begin{tabular}{lcc}
\hline ID Patients & N & P \\
\hline Male & 33 & $66 \%$ \\
Female & 17 & $34 \%$ \\
Total & 50 & $100 \%$ \\
\hline
\end{tabular}

Abbreviations: $\mathbf{N}=$ Total no of patients; $\mathbf{P}=$ Percentage

Table 2: Age distribution of patients with Intellectual Disability

\begin{tabular}{lllllll}
\hline Distribution & \multicolumn{1}{c}{$\mathbf{M}$} & \multicolumn{1}{c}{$\mathbf{P}$} & \multicolumn{1}{c}{$\mathbf{F}$} & \multicolumn{1}{c}{$\mathbf{P}$} & \multicolumn{1}{c}{$\mathbf{N}$} & \multicolumn{1}{c}{$\mathbf{P}$} \\
\hline $0-10$ & 21 & 42 & 12 & 24 & 33 & 66 \\
$11-20$ & 12 & 24 & 5 & 10 & 17 & 34 \\
Total & 33 & 100 & 17 & 100 & 50 & 100
\end{tabular}

Abbreviations: $\mathbf{M}=$ No. of Males; $\mathbf{F}=$ No. of Females; $\mathbf{N}=$ Total no of patients; $\mathbf{P}=$ Percentage

Table 3: Residential distribution of patients with Intellectual Disability

\begin{tabular}{ccc}
\hline Residence & N & P \\
\hline Rural & 20 & $40 \%$ \\
Urban & 30 & $60 \%$ \\
Total & 50 & $100 \%$ \\
\hline
\end{tabular}

Abbreviations: $\mathbf{N}=$ Total no of patients; $\mathbf{P}=$ Percentage

Prevalence of IQ levels and family history and their relation was recorded with ID and shown in table 4 and table 5. A high relation was recorded in ID and with more than 2 family members. 
Table 4: Prevalence of levels of IQ in patients with Intellectual Disability

\begin{tabular}{lcc}
\hline IQ Level & N & P \\
\hline Mild & 5 & $10 \%$ \\
Moderate & 8 & $16 \%$ \\
Severe & 35 & $70 \%$ \\
Profound & 2 & $4 \%$ \\
Total & 50 & $100 \%$
\end{tabular}

Abbreviations: $\mathbf{N}=$ Total no. of patients; $\mathbf{P}=$ Percentage

Table 5: Prevalence of Family History of ID in patients with Intellectual Disability

\begin{tabular}{lcc}
\hline Family History & N & P \\
\hline No Member & 0 & 0 \\
1 Member & 2 & $4 \%$ \\
2 Member & 5 & $10 \%$ \\
More than 2 Member & 43 & $86 \%$ \\
Total & 50 & $100 \%$ \\
\hline
\end{tabular}

Abbreviations: $\mathbf{N}=$ Total no of patients; $\mathbf{P}=$ Percentage

In all studied parameters history was $44 \%$ than other as phenylketonuria, of genetic disorder was also recorded and hypothyroidism and other disorders and ID was found high with microcephaly that shown in table 6.

Table 6: Prevalence of genetic disorders in patients of Intellectual Disability

\begin{tabular}{lcc}
\hline Disorder & N & P \\
\hline Microcephaly & 22 & $44 \%$ \\
Phenylketonuria & 2 & $4 \%$ \\
Hypothyroidism & 1 & $2 \%$ \\
Other disorder & 13 & $26 \%$ \\
Not any & 12 & $24 \%$ \\
Total & 50 & 100 \\
\hline
\end{tabular}

Abbreviations: $\mathbf{N}=$ Total no of patients; $\mathbf{P}=$ Percentage

Neonatal, postnatal and prenatal relation to ID and shown in table 7, table infections were also recorded with 8 and table 9 respectively. 
Table 7: Prevalence of Neonatal infection in patients of Intellectual Disability

\begin{tabular}{lcc}
\hline Neonatal infection & N & P \\
\hline Sever Jaundice & 5 & $10 \%$ \\
Hypoglycemic & 4 & $8 \%$ \\
Other & 21 & $42 \%$ \\
Not Any & 20 & $40 \%$ \\
Total & 50 & $100 \%$
\end{tabular}

Abbreviations: $\mathbf{N}=$ Total no of patients; $\mathbf{P}=$ Percentage

Table 8: Prevalence of Postnatal infection in patients of Intellectual Disability

\begin{tabular}{lcc}
\hline Postnatal infection & N & P \\
\hline Brain infection & 1 & $2 \%$ \\
Head injury & 1 & $2 \%$ \\
Malnutrition & 22 & $44 \%$ \\
Not Any & 26 & $52 \%$ \\
Total & 50 & $100 \%$ \\
\hline
\end{tabular}

Abbreviations: $\mathbf{N}=$ Total no of patients; $\mathbf{P}=$ Percentage

Table 9: Prevalence of Perinatal infection in patients of Intellectual Disability

\begin{tabular}{lcc}
\hline Perinatal infection & N & P \\
\hline Placental dysfunction & 10 & $20 \%$ \\
Sever Prematurity & 7 & $14 \%$ \\
Birth Trauma & 4 & $8 \%$ \\
Complicated Delivery & 19 & $38 \%$ \\
Others & 10 & $20 \%$ \\
Total & 50 & $100 \%$ \\
\hline
\end{tabular}

\begin{tabular}{|c|c|c|}
\hline \multicolumn{3}{|c|}{ Abbreviations: $\mathbf{N}=$ Total no. of patients; $\mathbf{P}=$ Percentage } \\
\hline \multicolumn{3}{|c|}{$\begin{array}{ll}\text { Other studied parameters such as } & \text { disability were also analyzed and in detail } \\
\text { chromosomal disorder, environment } & \begin{array}{l}\text { reported in table 10,111, 12, and } 13 \\
\text { influences, physical abnormality and }\end{array}\end{array}$} \\
\hline \multicolumn{3}{|c|}{ Table 10: Prevalence of chromosomal disorders in patients of Intellectual Disability } \\
\hline Chromosomal Disorder & $\mathbf{N}$ & $\mathbf{P}$ \\
\hline Down's syndrome & 21 & $42 \%$ \\
\hline Fragile X Syndrome & 10 & $20 \%$ \\
\hline Prader Willi Syndrome & 5 & $10 \%$ \\
\hline Klinefelter's Syndrome & 2 & $4 \%$ \\
\hline Other & 12 & $24 \%$ \\
\hline Total & 50 & $100 \%$ \\
\hline
\end{tabular}

Abbreviations: $\mathbf{N}=$ Total no of patients; $\mathbf{P}=$ Percentage 
Table 11: Prevalence of Environmental influences in patients of Intellectual Disability

\begin{tabular}{lcc}
\hline Environmental influences & N & P \\
\hline Malnutrition in pregnancy & 25 & $50 \%$ \\
Exposure to chemicals/radiations & 1 & $2 \%$ \\
Maternal infections & 5 & $10 \%$ \\
Rh incompatibility & 4 & $8 \%$ \\
Not Any & 15 & $30 \%$ \\
Total & 50 & $100 \%$ \\
\hline
\end{tabular}

Abbreviations: $\mathbf{N}=$ Total no of patients; $\mathbf{P}=$ Percentage

Table 12: Prevalence of Physical abnormalities in patients of Intellectual

\begin{tabular}{lcc}
\hline Physical abnormalities & N & P \\
\hline Floppy limb & 7 & $14 \%$ \\
Problem in feeding & 10 & $20 \%$ \\
Cleft lip & 5 & $10 \%$ \\
Large head & 10 & $20 \%$ \\
Weak limbs & 10 & $20 \%$ \\
Club feet & 5 & $10 \%$ \\
Lump on back & 1 & $2 \%$ \\
Lump on navel & 2 & $4 \%$ \\
\hline
\end{tabular}

Abbreviations: $\mathbf{N}=$ Total no of patients; $\mathbf{P}=$ Percentage

Table 13: Prevalence of signs of disability in patients of Intellectual Disability

\begin{tabular}{lcc}
\hline Signs of disability & N & P \\
\hline Delay in sitting & 10 & $20 \%$ \\
Delay in standing & 2 & $4 \%$ \\
Delay in walking & 2 & $4 \%$ \\
Visual disability & 1 & $2 \%$ \\
Hearing problem & 2 & $4 \%$ \\
Understanding disability & 10 & $20 \%$ \\
Moving limbs difficulties & 10 & $20 \%$ \\
Loses consciousness & 1 & $2 \%$ \\
Learning problem & 8 & $16 \%$ \\
Speak disability & 3 & $6 \%$ \\
Object recognition disability & 1 & $2 \%$ \\
\hline
\end{tabular}

$\mathbf{N}=$ Total no of patients; $\mathbf{P}=$ Percentage 
Intellectual disability (ID), also called as mental retardation, is defined by below-average intelligence or mental aptitude as well as a lack of life skills (Katusic et al., 1996). It is a cluster of syndromes and disorders characterized by low intelligence and associated limitations in adaptive behavior. People suffering from ID can and do learn new skills, but they do it at a slower pace. There are many levels of intellectual disability, ranging from mild to severe (Carulla et al., 2011). Injury, disease, or a malfunction in the brain can cause intellectual disability, traditionally known as mental retardation. The cause of intellectual impairment in many youngsters remains unknown. Down syndrome, Fetal Alcohol Syndrome, Fragile X syndrome, birth abnormalities, and infections are some of the causes of intellectual disability that can occur before birth. Other causes of intellectual disability, such as serious brain injury, infections, or stroke, do not manifest themselves until a kid is older (Ruparelia et al., 2013).

An IQ exam is used to determine one's IQ (intelligence quotient). The average IQ score is 100 , with the majority of persons scoring in the 85-115 range. If a person's IQ is between 70 and 75 , he or she is called intellectually handicapped. A professional will observe the child's skills and compare them to those of other children of the same age to determine the child's adaptive behaviors. The child's ability to feed and dress himself, as well as his or her ability to speak with and understand people, and how the child interacts with family, friends, and other children of the same age, are all things that can be seen. About $1 \%$ of the population is considered to be affected by intellectual disability. Of those affected, $85 \%$ have mild intellectual disability (Mayer et al., 2005).

Many of the parameters can cause ID. Microcephaly is the most frequent genetic abnormality related with ID, affecting 44 percent of patients $(\mathrm{N}=23)$. ID can be caused by a variety of factors, including environmental factors. The most prevalent is malnutrition in pregnancy, which affects $50 \%$ of mothers $(\mathrm{N}=25)$. Perinatal infections, neonatal infections, and postnatal infections are the three main causes of ID. Perinatal infection was found in 38 percent $(\mathrm{N}=$ 19) of the patients in this study during problematic delivery. About half of the patients $(\mathrm{N}=25)$ had severe jaundice, the most frequent newborn infection. Malnutrition infection is the most representative criterion in postnatal infection, accounting for 44 percent $(\mathrm{N}=$ 22) of patients.

The chi square was used to compare the different parameters studied, and P 0.05 was considered significant. In terms of age, gender, environmental effects, genetic condition, perinatal, neonatal, and postnatal infections, the findings were almost significant, according to the study. Subjective issues such as social isolation and life unhappiness may contribute to the high degree of stress or mental health problems 
experienced by parents of children with ID. The goal of this study was to give parents of ID patient's advice on how to help their children survive in the environment. This research has immediate and long-term consequences for the diagnosis and treatment of ID patients, and also advances our scientific understanding of this complicated disorder. Furthermore, it improved our knowledge of the prevalence of certain ID factors.

\section{CONCLUSION}

It was concluded there is a substantial delay in the discovery of intellectual disability, particularly in rural areas, where more than $70 \%$ of Pakistan's population lives. This wasted opportunity for early rehabilitation causes enormous distress for caregivers, who rarely obtain accurate information regarding the course, prognosis, and appropriate remedial measures. There is a need to develop community-level interventions that are practicable, cost-effective, and can be integrated into current healthcare systems.

\section{REFERENCES}

1. Brereton AV, Tonge BJ, Einfeld SL (2006). Psychopathology in children and adolescents with autism compared to young people with intellectual disability. J. Autism Develop. Disord. 36(7): 863-70.

2. Carulla LS, Reed GM, Cooper S, Saxena S (2011). Intellectual developmental disorders: towards a new name, definition and framework for "mental retardation/intellectual disability" in ICD-11. World Psychiatry. 10: 175-180.

3. Daily DK, Ardinger HH, Holmes GE (2000). Identification and evaluation of mental retardation. AFP. 61: 1059-1067.

4. Durkin M (2002). The epidemiology of developmental disabilities in low- income countries. Dev. Disabil. Res. Rev. 8: 206-211.

5. Durkin MS, Hasan ZM, Hasan KZ (1998). Prevalence and correlates of mental retardation among children in Karachi, Pakistan. Am. J. Epidemiol. 147(3): 281-288.

6. Guralnick MJ (2005). Early intervention for children with intellectual disabilities: Current knowledge and future prospects. J. Appl. Res. Intellect. Disabil. 18(4): 313-24.

7. Katusic SK, Colligan RC, Beard CM, O'Fallon, WM, Bergstralh EJ, Jacobsen SJ, Kurland LT (1996). Mental retardation in a birth cohort, 1976-1980, Rochester, Minnesota. AJMR. 100: 335-344. 
8. Maulik PK, Mascarenhas MN, Mathers CD, Dua T, Saxena S (2013). Prevalence of intellectual disability: A meta-analysis of population-based studies: Corrigendum.

9. Mayer AR, Mannell MV, Ling J, Gasparovic C, Yeo RA (2011). Functional connectivity in mild traumatic brain injury. Human brain mapping. 32(11): 18251835.

10. McLaren J, Bryson SE (1987). Review of recent epidemiological studies of mental retardation: prevalence, associated disorders, and etiology. AJMR.

11. Rauch A, Wieczorek D, Graf E, Wieland $\mathrm{T}$, Endele $\mathrm{S}$, Schwarzmayr T, Albrecht B, Bartholdi D, Beygo J, Di Donato N, Dufke A (2012). Range of genetic mutations associated with severe non-syndromic sporadic intellectual disability: an exome sequencing study. The Lancet. 380(9854): 1674-82.

12. Ropers HH (2006). X-linked mental retardation: many genes for a complex disorder. Curr Opin Genet Dev. 16: 260-269.

13. Ruparelia A, Pearn ML, Mobley WC (2013). Aging and intellectual disability: Insights from mouse models of down syndrome. Developmental disabilities research review, 18: 43-50.

14. Schalock RL, Luckasson RA, Shogren KA (2007). The renaming of mental retardation: Understanding the change to the term intellectual disability. Intellect. Develop. Disabil. 45(2): 116-24.

15. Wines M (2006). Malnutrition is cheating its survivors, and Africa's future. NYT. 28. 